\title{
Change in Faculty Perceptions of Burnout and Work Life in an Academic General Medicine Clinic: a Pre-Post Study
}

\author{
Jonathan S. Lee, MD, MAS , Leah S. Karliner, $M D, M A S^{1,2}$, Katherine A. Julian, $M D^{7}$, \\ Mark Linzer, MD ${ }^{3}$, and Mitchell D. Feldman, MD, MPhil ${ }^{1}$
}

'Division of General Internal Medicine, University of California San Francisco, San Francisco, CA, USA; ${ }^{2}$ Multiethnic Health Equity Research Center, University of California San Francisco, San Francisco, CA, USA; ${ }^{3}$ Department of Medicine, Hennepin Healthcare Systems and University of Minnesota, Minneapolis, MN, USA.

J Gen Intern Med 34(10): 1973-4

DOI: $10.1007 / \mathrm{s} 11606-019-05083-7$

(c) Society of General Internal Medicine 2019

\section{INTRODUCTION}

Burnout is prevalent among primary care physicians and contributes to job turnover and poor patient care. ${ }^{1}$ Interventions addressing adverse work conditions may reduce burnout. ${ }^{2} \mathrm{We}$ evaluated the impact of workflow and workload interventions targeted to physician-reported concerns following participation in a national academic general internal medicine burnout survey. ${ }^{1}$

\section{METHODS}

This was a pre-post intervention study of primary care physician faculty members of a large academic division of general internal medicine (GIM). In 2015, 3 focus groups were conducted with 20 physicians to better understand the physician experience in practice. Thematic content analysis identified a number of physician concerns including excessive clinic and home electronic health record (EHR) time as a primary driver of stress and work dissatisfaction. In particular, excessive EHR in-box message volume and cross-coverage responsibilities for residents and other faculty were felt to be unsustainable. In response, in 2015, division leadership commissioned the Association of Chiefs and Leaders in General Internal Medicine Work Life and Wellness Program to survey physicians based at 3 integrated clinics on symptoms of burnout, stress, and clinic work conditions using the mini- $Z$ survey and to compare institutional results to national results from academic GIM divisions. ${ }^{3}$ Specific evidence-based interventions were recommended (by author ML) and presented to health system leadership and a subset was implemented. A follow-up mini-Z survey was conducted in December 2017. We excluded faculty employed fewer than 6 months and performed a sensitivity analysis excluding faculty employed fewer than 12 months.
Survey results before and after intervention implementation were compared using unpaired chi-square tests. $P$ values less than 0.05 were considered statistically significant. This study was reviewed and exempted by the University of California San Francisco institutional review board.

\section{RESULTS}

Thirty-two of $42(76 \%)$ physicians completed the baseline survey in 2015 and $71 \%$ completed the follow-up survey 24 months later. At baseline, compared with results from other academic GIM divisions, study physicians reported higher burnout (56\% vs 33\%) and stress (88\% vs $65 \%$ ). The survey identified several other challenges, including lack of control over workload (63\% poor/marginal control study clinics vs $38 \%$ nationally), lack of time for documentation ( $81 \%$ insufficient time vs 54\%), and excessive time spent on the EHR at home $(81 \%$ vs $50 \%)$. Intervention recommendations to address the findings were discussed with executive leadership and the following were implemented between 2015 and 2017: (1) nurse practitioners hired to help with in-box management and coverage for physicians who are away; (2) decompressed clinic schedules by adding 2 administrative "desk top" slots to allow time for documentation and in-box management during the clinic day; (3) reduced wRVU productivity expectations for higher volume clinicians to correspond with the addition of "desk top" slots; and (4) transitioned to a blended compensation model in which half of clinical compensation was tied to empanelment and half remained wRVU-based. Follow-up surveys in 2017 demonstrated statistically significant improvements in symptoms of burnout (31\% in 2017 vs $56 \%$ in $2015, p=0.04)$ and stress $(63 \%$ vs $88 \%, p=0.02)$ (Table 1$)$. Of identified challenges, work control ( $31 \%$ poor control vs $63 \%, p=0.01)$ showed substantial improvement. Lack of documentation time $(59 \%$ vs $81 \%, p=0.06)$ and excessive home EHR time ( $63 \%$ vs $81 \%, p=0.1)$ also improved but did not reach statistical significance. Sensitivity analyses demonstrated similar findings for all comparisons. 
Table 1 Mini-Z Burnout and Work Conditions Survey Responses Before and After Implementation of Interventions Targeted to Physician Concerns.

\begin{tabular}{|c|c|c|c|}
\hline Survey item & $\begin{array}{l}\text { Pre-intervention } \\
2015 \\
N=32 / 42(76 \%)\end{array}$ & $\begin{array}{l}\text { Post-intervention } \\
2017 \\
N=32 / 45(71 \%)\end{array}$ & $P$ value $^{\dagger}$ \\
\hline $\begin{array}{l}\text { Overall, I am satisfied with my } \\
\text { current job (Agree, Strongly Agree) }\end{array}$ & $24(75 \%)$ & $26(81 \%)$ & 0.55 \\
\hline $\begin{array}{l}\text { I feel a great deal of stress because } \\
\text { of my job (Agree, Strongly Agree) }\end{array}$ & $28(88 \%)$ & $20(63 \%)$ & 0.02 \\
\hline $\begin{array}{l}\text { Single-item burnout measure (Definitely, } \\
\text { Won’t go away, Completely) } \$\end{array}$ & $18(56 \%)$ & $10(31 \%)$ & 0.04 \\
\hline My control over my workload is (Poor, Marginal) & $20(63 \%)$ & $10(31 \%)$ & 0.01 \\
\hline Sufficiency of time for documentation is (Poor, Marginal) & $26(81 \%)$ & $19(59 \%)$ & 0.06 \\
\hline $\begin{array}{l}\text { My professional values are well aligned } \\
\text { with those of my department leaders (Agree, Strongly Agree) }\end{array}$ & $26(81 \%)$ & $26(81 \%)$ & 1 \\
\hline $\begin{array}{l}\text { The degree to which my care team works } \\
\text { effectively together is (Satisfactory, Good, Optimal) }\end{array}$ & $21(66 \%)$ & $24(75 \%)$ & 0.41 \\
\hline $\begin{array}{l}\text { The amount of time I spend on the electronic } \\
\text { health record at home is (Moderately High, Excessive) }\end{array}$ & $26(81 \%)$ & $20(63 \%)$ & 0.1 \\
\hline $\begin{array}{l}\text { My proficiency with electronic health record } \\
\text { use is (Satisfactory, Good, Optimal) }\end{array}$ & $27(84 \%)$ & $30(94 \%)$ & 0.23 \\
\hline
\end{tabular}

Work atmosphere was not measured consistently between pre- and post-intervention and is not presented

${ }^{\dagger} P$ values were calculated using chi-square tests

${ }^{*}$ The single-item burnout measure asks respondents to use their own definition of burnout and to select one of the following answers: (1) I enjoy my work. I have no symptoms of burnout; (2) I am under stress, and do not always have as much energy as I did, but I do not feel burned out; (3) I am definitely burning out and have one or more symptoms of burnout, e.g., emotional exhaustion; (4) The symptoms of burnout that I am experiencing will not go away. I think about work frustrations a lot; (5) I feel completely burned out. I am at the point where I may need to seek help

\section{DISCUSSION}

We found statistically significant improvements in symptoms of burnout and stress following targeted interventions to support faculty physicians at an academic GIM practice. Our study has implications for other GIM divisions. First, burnout and its drivers can be measured as a means of engaging physicians and health system leadership to make targeted interventions. Second, shifting from volume to value-i.e., toward empanelment-based primary care compensation-may improve stress and burnout and merits further study. Third, we found impressive increments in perceived control over workload, an important driver of workplace stress and burnout. ${ }^{4}$ While this improvement is likely multifactorial in etiology, the implementation of "desk top" slots, which have been described by others, likely contributed and can be implemented quickly. ${ }^{5}$ Strengths of our study include a high survey response rate and the ability to compare our findings to a national sample of academic GIM divisions. Limitations include the pre-post and single-site study design and our use of the mini- $Z$ single-item assessment of burnout symptoms, which correlates primarily with the emotional exhaustion domain of burnout and may not capture respondents scoring highly in other domains. ${ }^{6}$

Corresponding Author: Jonathan S. Lee, MD, MAS; Division of General Internal Medicine, University of California San Francisco, San Francisco, CA, USA (e-mail: jonathan.lee2@ucsf.edu).

\section{Compliance with Ethical Standards:}

This study was reviewed and exempted by the University of California San Francisco institutional review board.

Conflict of Interest: Dr. Linzer consulted for UCSF to measure burnout. Funds for this consultation were donated to the Hennepin Health Foundation to support wellness activities and research. All remaining authors declare that they do not have a conflict of interest.

\section{REFERENCES}

1. Linzer M, Poplau S, Babbott S, et al. Worklife and wellness in academic general internal medicine: results from a national survey. J Gen Intern Med. 2016;31(9):1004-1010

2. Panagioti M, Panagopoulou E, Bower $\mathbf{P}$, et al. Controlled interventions to reduce burnout in physicians: a systematic review and meta-analysis. JAMA Intern Med. 2017;177(2):195-205.

3. American Medical Association Steps Forward. Preventing Physician Burnout. https://edhub.ama-assn.org/steps-forward/module/2702509. Accessed May 1, 2019.

4. Karasek R, Baker D, Marxer F, Ahlbom A, Theorell T. Job decision latitude, job demands, and cardiovascular disease: a prospective study of Swedish men. Am J Public Health. 1981;71(7):694-705.

5. Reid RJ, Fishman PA, Yu O, et al. Patient-centered medical home demonstration: a prospective, quasi-experimental, before and after evaluation. Am J Manag Care. 2009;15(9):e71-87.

6. Dyrbye LN, Meyers D, Ripp J, Dalal N, Bird SB, Sen S. A Pragmatic Approach for Organizations to Measure Health Care Professional WellBeing. Washington, DC: Discussion Paper, National Academy of Medicine;2018.

Publisher's Note Springer Nature remains neutral with regard to jurisdictional claims in published maps and institutional affiliations. 